\title{
Patterns of Health-Risk Behaviors among Jordanian Adolescent Students
}

\author{
Malakeh Z. Malak \\ Community Health Nursing, Faculty of Nursing, Zarqa University, Zarqa, Jordan \\ Email: malakehmalak@yahoo.com
}

Received 9 November 2014; accepted 17 December 2014; published 14 January 2015

Copyright @ 2015 by author and Scientific Research Publishing Inc.

This work is licensed under the Creative Commons Attribution International License (CC BY). http://creativecommons.org/licenses/by/4.0/

c) (i) Open Access

\section{Abstract}

Little information exists about health-risk behaviors in Jordanian adolescents especially among 15 19 years olds. The purpose of this study was to assess the patterns of three of health-risk behaviors, namely, diet, physical activity, and tobacco use of the Jordanian adolescent students aged 15 to 19 years old, and to compare the patterns of these behaviors between male and female adolescents. A descriptive cross-sectional design was used. A multi-stage stratified random sample was obtained from the public school educational directorate, which is affiliated to Amman governorate. A random sub sample of eight public comprehensive secondary schools was selected, four schools for females and four schools for males. A total of 750 students (375 boys and 375 girls), their ages between 15 - 19 years were included in the analysis. Data were collected by using two tools: students' profile structured questionnaire (tool 1), and a modified version of the General School Health Survey questionnaire (tool 2). The findings of this study showed that $10.7 \%$ of students were overweight and $4.9 \%$ were obese. The majority of students had eaten less than the daily requirements of fruits, vegetables, and milk daily, while the intake of soft drinks was higher than recommended. One-fifth of students had been physically active at least 60 minutes daily. Overall, (55.5\%) had tried smoking and $\mathbf{4 4 . 0 \%}$ had smoked any other form of tobacco such as water pipe. Moreover, $62.4 \%$ had tried to quit smoking cigarettes. Furthermore, there were significant differences between males and females regarding these risk behaviors. In conclusion, there are problems with Jordanian adolescents relating to diet, physical activity, and tobacco use. The results highlight the need for effective school health program that combines education, counseling and behavioral skill building along with environmental support to enhance students' efforts, intentions, and strategies to overcome these risk behaviors. In addition, the findings could help policy makers to strength strategies and policies to maintain healthy adolescents and schools.

\section{Keywords}

Adolescents, Diet, Nutrition, Physical Activity, Tobacco Use 


\section{Introduction}

The adolescence period represents a phase that for many individuals signifies an important transition from childhood to adulthood [1]. Adolescents in this period experience more freedom, independence, and normative experimentation accompanied by more peer pressure and less parental supervision, which results in weaker inhibitions to engage in any healthy or unhealthy behaviors [2] [3]. Available evidence suggests that adolescents engage in variety of risky behaviors, including smoking, alcohol and drug use and abuse, poor diets and sedentary lifestyles, which leads to overweight and obesity, vehicular speeding, lack of seatbelt use, and risky sexual behavior [4], which make them susceptible to serious physical and mental problems. In addition, these behaviors contribute to educational and social problems among students [5].

Risky health behaviors that arise during adolescence have a serious impact on the health and development of adolescents and young people's current health status, and increased risk for developing chronic diseases in adulthood [6]. In addition, they are considered as a major source of preventable premature deaths [7].

Adolescents (ages 10 to 19) make up 22.92\% of the population of the Jordan, $11.95 \%$ of them ages between 10 - 14 years and $10.97 \%$ between 15 - 19 years [8]. In Jordan, unfortunately, little information exists about health-risk behaviors in Jordanian adolescents especially among 15 - 19 years. There are few studies done in the last decade addressing the health-risk behaviors and health aspects of Jordanian adolescent students. The conducted studies focused primarily on students aged 13 - 15 years [9] [10] and on the health wellness behaviors [11]. The most recent evidence revealed that $17.5 \%$ of schoolchildren, aged 13 to 15 years in Jordan, were either overweight or obese, while only $14.3 \%$ were physically active, and one in five students used tobacco [10].

Lifestyle and self-care behaviors are formed during childhood and adolescence. Providing adolescents with basic health information and skills may reduce future health risks by promoting enhanced self-care practices that include opportunities for active engagement in health promotion program planning. Health promotion in persons in this age group is primarily one of health teaching and guidance [12]. Moreover, more effective school health programs and other policy and programmatic interventions are needed to reduce risk and improve health outcomes among adolescents [13].

This study provided accurate and appropriate systematic assessment of health-risk behaviors among adolescent students aged 15 to 19 years. Identification of these risk behaviors is essential for health care professionals and counselors in students' schools and in the primary health settings to understand the nature of risk behaviors, and to plan better for early interventions. This information might help health care professionals to develop interventional programs that focus on improving students' health, and to implement cultural specific intervention and health promotion programs. Therefore, the purpose of this study was to assess the patterns of three of health-risk behaviors, namely, diet, physical activity, and tobacco use of the Jordanian adolescent students aged 15 to 19 years old, and to compare the patterns of these behaviors between male and female adolescents.

\section{Methods}

\subsection{Design, Setting, and Sample}

A descriptive cross sectional design was used to conduct this study. The study was carried out in the city of Amman in Jordan; Amman is the capital and most populous city in the country. A multi-stage stratified random sample was obtained by first selecting the public school educational directorate located in the city of Amman. Amman's public schools are arranged in five zones: the first, the second, the third, the fourth and the fifth. Public schools in Jordan are single sex. The sample size was estimated based on the medium effect size at power of 0.80 and $\alpha$ of 0.05 [14].

The system for selecting participants was as follow: two zones of five zones were selected by random drawing. Thereafter, four public comprehensive secondary schools from each zone were selected randomly (divided into two male and two female schools). The tenth, the first and the second secondary classes were selected. Individual classes of students were then selected randomly by using simple random sampling technique until a sample size of 750 students (375 females and 375 males) aged between 15 - 19 years was achieved. Students who had physical immobility or had any chronic illness such as thyroid disease or diabetes mellitus were excluded from participation. 


\subsection{Procedures}

One class of the tenth grade consisted of 28 - 32 students was randomly selected from each school. In addition, seven to ten students from each available section (Scientific, Literary, Information Technology, Health education, and Home economics) in the first and the second secondary grades were selected randomly. Data was collected from all classes of students at each study site on the same day. A brief description of the study's purpose in addition to instructions of using the questionnaire was given to the students at the beginning. Participation was voluntary and anonymous. Additionally, the teachers were requested to not be present during the actual filling and submission of the completed questionnaires. Participants' guardian informed consents were considered and parental approval was obtained. After questionnaires were distributed, anthropometric measurements were obtained. Administration and collection of questionnaires for each class required approximately 15 - 20 minutes. Ethical approvals were obtained from the Ministry of Education, the selected educational zones, and the participating schools. Data was collected from February to April 2014.

\subsection{Instruments}

A self-reported questionnaire was used and consisted of two tools that were used in the process of data collection. These tools include Students' Profile Structured questionnaire that includes personal and socio-demographic data and sources of health-related information, which was developed by the researcher and based on the literature review. In addition, a modified version of the Global School-based Student Health Survey Questionnaire (GSHS), which was originally developed by the Center for Disease Control and Prevention [9] and based on Youth Risk Behaviors Surveillance (YRBS) questionnaire [15]. The Global School-based Student Health Survey is a school-based survey conducted primarily among students aged 13 - 15 years. It measures behaviors and protective factors related to the leading causes of mortality and morbidity among youth and adults, which includes alcohol and other drug use, dietary behaviors, hygiene, mental health, physical activity, protective factors, sexual behaviors that contribute to HIV infection, tobacco use, violence and unintentional injury. These tools were used in different locations in the world to assess health-risk behaviors among adolescents [9] [10] [15] [16].

From this instrument, only the areas about dietary behaviors, physical activity and tobacco use were used. Thirty-two questions were used from the GSHS global core modules and five additional questions were added from the (YRBS) questionnaire to expand set of questions. Since Arabic is the native language in Jordan, the Arabic version of GSHS questionnaire was used. In addition, five added questions were translated into Arabic version. These tools were reviewed for both translational and cultural appropriateness.

The Arabic version of the instrument was then pilot tested on 60 (30 males and 30 females) students in order to test data collection procedures and compute the reliability coefficient of the Arabic version. According to the pilot study result, questions were clear to most of students. Internal consistency was used in ascertaining reliability of the instrument between individual items in the scale. The Cronbach's Alpha obtained from the pilot data was 0.84 . The final Arabic version questionnaire consisted of the following subscales: dietary behaviors subscale that consisted of 18 items related to body weight, nutritional patterns, and education about body weight and nutrition; physical activity subscale that consisted of nine items related to physical behaviors and education about physical activity; and tobacco use subscale that consisted of ten items related to tobacco use indoor and in schools. All three subscales items were scored on various Likert-type scale.

In addition, measurements of the weights and heights were obtained to calculate body mass index (BMI). Body Mass Index results were compared to the BMI classifications by Center for Disease Control and Prevention BMI for age growth charts [10] as follow: underweight (BMI is less than 5th percentile), normal weight (BMI is 5th - <85th percentile), overweight (BMI is at or above the 85th percentile, but below or at the 95th percentile) or obesity (BMI is above the 95th percentile). Body Mass Index was calculated as BMI $=\mathrm{kg} / \mathrm{m}^{2}$.

\subsection{Statistical Analysis}

The statistical Package of the Social Science (SPSS) version 17 was used to compute all data in this study. Descriptive statistics were used and included frequencies and percentages. Chi-square $\left(X^{2}\right)$ was used to examine gender differences. The significance level was tested at alpha $\leq 0.05$. 


\section{Results}

The total number of adolescent students who participated in the study was 750 . They equally divided into male and female students. Regarding family income, the majority of students (44.9\%) reported to be having enough and sparing no income. Almost one-third of them (33.3\%) described their academic grades to be "very good", whereas $26.4 \%$ described their grades to be "excellent" and the rest showed medium to good averages with very few revealed "weak" levels.

A majority of students from both genders (57.5\%) reported that the family is the primary source of information, followed by mass media (22.6\%), friends (14.8\%), then teachers (3.5\%), and finally health team members $(1.6 \%)$. There were no significant differences in source of information between male and female students $\left(X^{2}=\right.$ $7.48, \mathrm{p}>0.05)$.

\subsection{Dietary Behaviors}

Table 1 presents findings related to body weight. The findings of body mass index (BMI) revealed that 10.7\% of students were overweight and $4.9 \%$ of them were obese. Significant gender differences were found in which males were more overweight, obese and underweight than females $\left(X^{2}=15.9, \mathrm{p} \leq 0.05\right)$. Overall, $52.8 \%$ of students considered themselves to have a normal weight, and $35.3 \%$ of them were trying to lose weight. Female students (43.7\%) were significantly more likely (26.9\%) of trying to lose weight than male students $\left(X^{2}=35.26\right.$, $\mathrm{p} \leq 0.05$ ). The methods of losing weight or keeping it from gaining were used were: practicing exercise (49.6\%), followed by not eating for 24 or more hours (13.1\%), and using diet pills, powders, or liquids without a doctor's advice (8.7\%). Moreover, $14.7 \%$ of students reported that they were taught in any school classes' healthy ways to gain weight and $18.8 \%$ of them were taught healthy ways to lose weight during this school year. Significantly, females were more likely were taught about healthy ways to gain weight $\left(X^{2}=13.29, \mathrm{p}=0.00\right)$ and to lose weight $\left(X^{2}=26.05, \mathrm{p} \leq 0.05\right)$ than males.

Table 2 presents findings related to nutritional habits. Findings indicated that more than one-third of students had eaten breakfast 5 - 7 days weekly (41.2\%), and about 37.7\% of them had eaten breakfast 1 day or less weekly. Males were significantly better than females about eating daily breakfast $\left(X^{2}=15.35, \mathrm{p} \leq 0.05\right)$. The main reasons for not eating breakfast were not having time for breakfast (29.3\%), followed by finding difficulty to eat early in the morning (28.0\%). Almost one-quarter of students (23.4\%) had drunk $100 \%$ fresh juice one or more times daily. The majority of students indicated that they had eaten fruits less than four times daily (93.9\%) and vegetables less than four times daily (94.8\%). In addition, 91.9\% indicated that they had drunk milk or dairy products less than four times daily. Males were significantly better concerning drinking milk or dairy products than females $\left(X^{2}=14.64, \mathrm{p} \leq 0.05\right)$. Moreover, a majority of students $(58.8 \%)$ indicated that they had drunk soft drinks one and more times daily. Males (46.1\%) were significantly more likely (31.7\%) having drunk soft drinks than females $\left(X^{2}=36.86, \mathrm{p} \leq 0.05\right)$. On the other hand, $25.2 \%$ of the students had eaten fast food once a day, while $29.6 \%$ had eaten fast food two to seven times daily (33.1\% were males and $26.1 \%$ were females). About one-quarter of students received education about benefits of fruits and vegetables and $27.9 \%$ of them received education bout benefits of milk and dairy products during this academic year. Females were significantly better in regard to education about benefits of fruits and vegetables $\left(X^{2}=30.70, \mathrm{p} \leq 0.05\right)$ and benefits of milk and dairy products $\left(X^{2}=62.42, \mathrm{p} \leq 0.05\right)$ than males.

\subsection{Physical Activity}

Table 3 presents physical activity behaviors of students. Findings indicated that one-fifth of students (20.1\%) had been physically active at least 60 minutes daily on all past 7 days. In addition, 18.0\% of students had been physically active for a total of at least 60 minutes daily on all 7 days during past a typical or usual week. Almost one-tenth of students (10.4\%) had participated in muscle strengthening exercises (e.g., push-ups, sit-ups, or weight lifting) on three or more days during the past 7 days. The majority of students (47.5\%) watched television three or more hours daily on an average school day. Moreover, $27.0 \%$ of students played video or computer games or used a computer for something that was not schoolwork for three or more hours daily on an average school day. A total of $17.6 \%$ of students attended physical education (PE) classes on one or more days in an average week when they were in school. Females were significantly less likely than males about attending physical education classes $\left(X^{2}=21.28, \mathrm{p} \leq 0.05\right)$. Moreover, more than one-third of students (38.8\%) did not walk or 
Table 1. Body weight by sex $(\mathrm{N}=750$; Female $\mathrm{N}=375$; Male $\mathrm{N}=375)$.

\begin{tabular}{|c|c|c|c|c|c|}
\hline \multirow{3}{*}{ Item } & \multirow{2}{*}{\multicolumn{2}{|c|}{ Total (N) }} & \multicolumn{2}{|c|}{ Sex } & \multirow{3}{*}{ Test $X^{2}$} \\
\hline & & & \multirow{2}{*}{$\begin{array}{c}\text { Male } \\
\%\end{array}$} & \multirow{2}{*}{$\begin{array}{c}\text { Female } \\
\%\end{array}$} & \\
\hline & $\mathrm{N}$ & $\%$ & & & \\
\hline \multicolumn{6}{|l|}{ Body mass index } \\
\hline Less than 5th percentile & 59 & 7.9 & 10.1 & 5.6 & \multirow{4}{*}{$\begin{array}{l}X^{2}=15.9 \\
p=0.00^{*}\end{array}$} \\
\hline 5th - 85th percentile & 574 & 76.5 & 70.4 & 82.6 & \\
\hline 85th - 95th percentile & 80 & 10.7 & 13.1 & 8.3 & \\
\hline < 95th percentile & 37 & 4.9 & 6.4 & 3.5 & \\
\hline \multicolumn{6}{|l|}{ Described body weight } \\
\hline Very underweight & 33 & 4.4 & 5.1 & 3.7 & \multirow{5}{*}{$\begin{array}{c}X^{2}=4.25 \\
\mathrm{p}=0.37\end{array}$} \\
\hline Slightly underweight & 110 & 14.7 & 16.5 & 12.8 & \\
\hline About the right weight & 396 & 52.8 & 52.8 & 52.8 & \\
\hline Slightly overweight & 174 & 23.2 & 21.1 & 25.3 & \\
\hline Very overweight (Obese) & 37 & 4.9 & 4.5 & 5.3 & \\
\hline \multicolumn{6}{|l|}{ Tried to do about weight } \\
\hline Lose weight & 265 & 35.3 & 26.9 & 43.7 & \multirow{4}{*}{$\begin{aligned} X^{2} & =35.26 \\
\mathrm{p} & =0.00^{*}\end{aligned}$} \\
\hline Gain weight & 146 & 19.5 & 22.4 & 16.5 & \\
\hline Stay the same weight & 104 & 13.9 & 19.5 & 8.3 & \\
\hline I am not trying to do anything about my weight & 235 & 31.3 & 31.2 & 31.5 & \\
\hline \multicolumn{5}{|l|}{$\begin{array}{l}\text { Did not eat for } 24 \text { hours or more (also called } \\
\text { fasting) to lose weight or to keep from gaining } \\
\text { weight during the past } 30 \text { days }\end{array}$} & \multirow{3}{*}{$\begin{array}{l}X^{2}=3.80 \\
p=0.05^{*}\end{array}$} \\
\hline Yes & 98 & 13.1 & 10.7 & 15.5 & \\
\hline No & 652 & 86.9 & 89.3 & 84.5 & \\
\hline \multicolumn{5}{|l|}{$\begin{array}{l}\text { Took any diet pills, powders, or liquids or taking } \\
\text { laxatives without a doctor's advice to lose weight or } \\
\text { to keep from gaining weight during the past } 30 \text { days }\end{array}$} & \multirow{3}{*}{$\begin{array}{l}X^{2}=0.83 \\
\mathrm{p}=0.36\end{array}$} \\
\hline Yes & 65 & 8.7 & 7.7 & 9.6 & \\
\hline No & 685 & 91.3 & 92.3 & 90.4 & \\
\hline \multicolumn{5}{|l|}{$\begin{array}{l}\text { Did exercise to lose weight or to keep from } \\
\text { gaining weight during the past } 30 \text { days. }\end{array}$} & \multirow{3}{*}{$\begin{array}{l}X^{2}=1.05 \\
p=0.31\end{array}$} \\
\hline Yes & 372 & 49.6 & 51.5 & 47.7 & \\
\hline No & 378 & 50.4 & 48.5 & 52.3 & \\
\hline
\end{tabular}

*Significant at $\mathrm{p}<0.05 ; \%$ Percentage.

Table 2. Nutritional Patterns by sex $(\mathrm{N}=750$; Female $\mathrm{N}=375$; Male $\mathrm{N}=375$ ).

\begin{tabular}{|c|c|c|c|c|c|}
\hline \multirow{3}{*}{ Item } & \multirow{2}{*}{\multicolumn{2}{|c|}{ Total (N) }} & \multicolumn{2}{|c|}{ Sex } & \multirow{3}{*}{ Test $X^{2}$} \\
\hline & & & Male & Female & \\
\hline & $\mathrm{N}$ & $\%$ & $\%$ & $\%$ & \\
\hline \multicolumn{6}{|c|}{ Times a week ate breakfast } \\
\hline 0 days & 196 & 26.1 & 23.5 & 28.8 & \multirow{8}{*}{$\begin{aligned} X^{2} & =15.35 \\
p & =0.03^{*}\end{aligned}$} \\
\hline One day & 87 & 11.6 & 10.7 & 12.5 & \\
\hline Two days & 143 & 19.1 & 17.1 & 21.1 & \\
\hline Three days & 10 & 1.3 & 2.4 & 0.3 & \\
\hline Four days & 5 & 0.7 & 0.5 & 0.8 & \\
\hline Five days & 9 & 1.2 & 1.3 & 1.1 & \\
\hline Six days & 22 & 2.9 & 3.7 & 2.1 & \\
\hline Seven days & 278 & 37.1 & 40.8 & 33.3 & \\
\hline
\end{tabular}




\section{Continued}

Times a week drank $100 \%$ fruit juices

I did not drink $100 \%$ fruit juice

246

1 to 3 times

4 to 6 times

1 time per day

2 times per day

3 times per day

4 or more times per day

Fruits intake per week

I did not eat fruit

1 to 3 times

4 to 6 times

1 time per day

2 times per day

3 times per day

4 or more times per day

Vegetables intake per week

I did not eat green salad

1 to 3 times

4 to 6 times

1 time per day

2 times per day

3 times per day

4 or more times per day

Times a day drank milk or its products

I did not drink

Less than one time per day

1 time per day

2 times per day

3 times per day

4 times per day

5 or more times per day

Soft drink intake per week

I did not drink

Less than 1 time per day

1 time per day

2 times per day

3 times per day

4 times per day

5 or more times per day

Fast food intake per week

0 days
1 day
2 days
3 days
4 days
5 days
6 days
7 days

0 days

1 day

2 days

4 days

5 days

7 days

32.9
35.3
8.4
14.1
5.9
2.1
1.3

29.1

37.3

8.0

14.7

6.4

3.2

1.3

\section{2}

25.3

25.6

16.8

12.3

4.8

8.0

$$
X^{2}=11.76
$$$$
\mathrm{p}=0.07
$$

11.7

5.3

4.3

6.1

8.1

6.7

23.7

24.5

22.1

13.6

3.5

5.9

$X^{2}=5.01$

$\mathrm{p}=0.54$

23.7

10.1

4.0

4.5

5.2

14.5

23.1

11.7

23.5

23.7

20.0

9.9

5.6

5.6

17.3

22.7

21.6

22.4

10.9

1.9

3.2

$X^{2}=14.64$

$\mathrm{p}=0.02^{*}$

3.7

4.4

15.6

25.6

19.9

15.7

10.8

4.9

7.5

8.8

22.4

25.1

20.8

14.9

8.0

4.0

4.8

$$
\begin{aligned}
X^{2} & =36.86 \\
\mathrm{p} & =0.00^{*}
\end{aligned}
$$

13.6

5.9

10.1

42.9

47.5

26.4

14.9

6.7

2.4

0.8

0.5

1.1

$$
\begin{aligned}
X^{2} & =10.93 \\
p & =0.14
\end{aligned}
$$

\footnotetext{
* Significant at p $\leq$ 0.05; \% Percentage.
} 
Table 3. Physical activity behaviors by sex $(\mathrm{N}=750$; Female $\mathrm{N}=375$; Male $\mathrm{N}=375)$.

\begin{tabular}{|c|c|c|c|c|c|}
\hline \multirow{3}{*}{ Item } & \multirow{2}{*}{\multicolumn{2}{|c|}{ Total (N) }} & \multicolumn{2}{|c|}{ Sex } & \multirow{3}{*}{ Test $X^{2}$} \\
\hline & & & Male & Female & \\
\hline & $\mathrm{N}$ & $\%$ & $\%$ & $\%$ & \\
\hline
\end{tabular}

Physically active for a total of at least 60 minutes per day during the past seven days

$\begin{array}{lcccc}0 \text { days } & 125 & 16.7 & 12.3 & 21.1 \\ 1 \text { day } & 111 & 14.8 & 11.5 & 18.1 \\ 2 \text { days } & 88 & 11.7 & 10.1 & 13.3 \\ 3 \text { days } & 89 & 11.9 & 15.2 & 8.5 \\ 4 \text { days } & 57 & 7.6 & 8.6 & 6.7 \\ 5 \text { days } & 83 & 11.1 & 13.3 & 8.8 \\ 6 \text { days } & 46 & 6.1 & 5.3 & 6.9 \\ 7 \text { days } & 151 & 20.1 & 23.7 & 16.5\end{array}$

Exercises to strengthen or tone muscles, such as pushups, sit-ups, or weight lifting during the past seven days

$$
\begin{aligned}
& 0 \text { days } \\
& 1 \text { day } \\
& 2 \text { days } \\
& 3 \text { days } \\
& 4 \text { days } \\
& 5 \text { days } \\
& 6 \text { days } \\
& 7 \text { days }
\end{aligned}
$$

407

Hours of watching T.V on an average school day

Play video or computer games or use a computer Do not watch TV

Less than 1 hour per day

$$
\begin{aligned}
& 1 \text { hour per day } \\
& 2 \text { hours per day } \\
& 3 \text { hours per day } \\
& 4 \text { hours per day }
\end{aligned}
$$

5 or more hours per day for something thatis not school work on an average school day

$$
\text { Do not play }
$$

Less than 1 hour per day

1 hour per day

2 hours per day

3 hours per day

4 hours per day

5 or more hours per day

36

Time usually taken each day to get to and from school during the past seven days

Less than 10 minutes per day

10 to 19 minutes per day

20 to 29 minutes per day

30 to 39 minutes per day

40 to 49 minutes per day

50 to 59 minutes per day

60 or more minutes per day

$\begin{array}{lcccc}211 & 28.1 & 29.6 & 26.7 & \\ 249 & 33.2 & 30.4 & 36.0 & X^{2}=7.13 \\ 128 & 17.1 & 16.3 & 17.9 & \mathrm{p}=0.31 \\ 73 & 9.7 & 9.3 & 10.1 & \\ 22 & 3.0 & 3.7 & 2.1 & \\ 13 & 1.7 & 1.9 & 1.6 & \\ 54 & 7.2 & 8.8 & 5.6 & \end{array}$

*Significant at $\mathrm{p} \leq 0.05$; \% Percentage. 
bicycle to and from school. Overall, 78.4\% of students usually took less than 30 minutes to get to and from school each day. The results showed that there was a significant difference between males and females about physical activity as shown in Table 3.

Almost one-quarter of students (26.0\%) were taught in any school classes' benefits of physical activity and $8.0 \%$ were taught about opportunities for physical activity in community during this school year. Female students were significantly more likely to be received education about physical activity than males $\left(X^{2}=14.54, \mathrm{p} \leq\right.$ $0.05)$.

\subsection{Tobacco Use}

Table 4 presents findings related to tobacco use. Findings indicated that the majority of students had tried smoking even one or two puffs (66.4\% among males and 44.5\% among females, respectively). Overall, $16.7 \%$ of students had smoked at the age of 13 or 14 years (21.9\% among male students and $11.5 \%$ among female students). Almost one-third of students (36.1\%) had smoked cigarettes on one or more days. Moreover, 8.3\% of them had smoked more than ten cigarettes daily. In addition, $64.2 \%$ of smokers had usually obtained their own cigarettes by buying them in a store (e.g., convenience store, supermarket, or discount store or gas station), followed by borrowing from someone else (16.6\%), and taking them from a store or family member (15.5\%), while (3.7\%) were giving someone else money to buy them. Significant gender differences were found in male preference for buying cigarettes (86.9\%), and female preference for taking them from a store or family member (39.6\%) $\left(X^{2}=143.08 ; \mathrm{p} \leq 0.05\right)$. Almost one-tenth of students $(11.5 \%)$ had smoked cigarettes on school property on at least one day. Moreover, $44.0 \%$ of students had smoked any other form of tobacco such as water pipe on at least one day during the past 30 days. Among students who currently smoked cigarettes, $62.4 \%$ had tried to quit smoking cigarettes. Overall, $84.7 \%$ of students reported that people had smoked in their presence on one or more days during the past seven days. Overall, $41.7 \%$ of students had a parent or guardian who smoked any form of tobacco. There were significant differences between genders in all subscale items; male students were significantly more likely than female students to have tobacco use behaviors as shown in Table 4 .

\section{Discussion}

\subsection{Dietary Behaviors}

The results of this study showed that $76.5 \%$ of students had normal body weight, $10.7 \%$ were overweight and $4.9 \%$ were obese. Males were more likely to have overweight and obesity than females. This figure is different from a previous Jordanian study, which showed that $71.3 \%$ of students had normal weight, $15.7 \%$ overweight and $8.7 \%$ obese [17]. This might be indicative of the influence of cultural and socioeconomic factors on preventive behaviors regarding weight. Another previous Jordanian study showed that $14.3 \%$ of students were overweight and $3.9 \%$ were obese [10].

The present findings showed that the majority of students (52.8\%) described their weight as about the right weight although two-thirds of them have normal body weight. In addition, males were more likely to perceive themselves as underweight, and females were more likely to perceive themselves as overweight. These findings are congruent with other previous studies [15] [18]. This result might be explained by existence of confusion and lack of awareness among adolescents regarding their body weight.

This study found that about one-third of students (35.3\%) had tried to lose weight, which is consistent with Center for Disease Control and Prevention study [10], which showed that 34.9\% of Jordanian adolescents had tried to lose weight. On the contrary, this result is low compared to similar age groups in U.S. Center for Disease Control and Prevention study [15], which found that $47.7 \%$ of adolescents had tried to lose weight. The present findings further showed that physical exercise was the predominant way to lose weight or to keep from gaining (49.6\%), while a previous Jordanian study showed that $47.5 \%$ of adolescents used laxatives and $49.1 \%$ used diet pills to decrease body weight [11].

The findings of this study showed that, although $41.2 \%$ of students had eaten breakfast from five to seven days weekly, still $26.1 \%$ of students had not eaten breakfast at all. These results are incongruent with Arabic studies' findings. For example, Haddad et al. [11] reported that 56.4\% of Jordanian students aged 12 - 17 years had eaten breakfast from 5 to 7 days weekly and $16.8 \%$ of students had not eaten breakfast. In Bahrain, $51.7 \%$ of adolescents aged between 14 - 19 years had eaten breakfast on the daily basis [19] which is comparable to 
Table 4. Tobacco use behaviors by sex $(\mathrm{N}=750$; Female $\mathrm{N}=375$; Male $\mathrm{N}=375$ ).

\begin{tabular}{|c|c|c|c|c|c|}
\hline \multirow{3}{*}{ Item } & \multirow{2}{*}{\multicolumn{2}{|c|}{ Total (N) }} & \multicolumn{2}{|c|}{ Sex } & \multirow{3}{*}{ Test $X^{2}$} \\
\hline & & & \multirow{2}{*}{$\begin{array}{c}\text { Male } \\
\%\end{array}$} & \multirow{2}{*}{$\begin{array}{c}\text { Female } \\
\%\end{array}$} & \\
\hline & $\mathrm{N}$ & $\%$ & & & \\
\hline \multicolumn{5}{|c|}{ Had tried cigarette smoking (even one or two puffs) } & \multirow{3}{*}{$\begin{aligned} X^{2} & =36.30 \\
p & =0.00^{*}\end{aligned}$} \\
\hline Yes & 416 & 55.5 & 66.4 & 44.5 & \\
\hline No & 334 & 44.5 & 33.6 & 55.5 & \\
\hline \multicolumn{6}{|c|}{ Age of smoking a whole cigarette for the first time } \\
\hline Never smoked a whole cigarette & 334 & 44.5 & 33.6 & 55.5 & \multirow{7}{*}{$\begin{aligned} X^{2} & =67.79 \\
p & =0.00^{*}\end{aligned}$} \\
\hline 8 years old or younger & 34 & 4.5 & 6.1 & 2.9 & \\
\hline 9 or 10 years old & 24 & 3.2 & 4.5 & 1.9 & \\
\hline 11 or 12 years old & 44 & 5.9 & 10.1 & 1.6 & \\
\hline 13 or 14 years old & 125 & 16.7 & 21.9 & 11.5 & \\
\hline 15 or 16 years old & 128 & 17.1 & 17.6 & 16.5 & \\
\hline 17 years old or older & 61 & 8.1 & 6.1 & 10.1 & \\
\hline
\end{tabular}

Number of days cigarettes smoked during the past 30 days

$\begin{array}{ccccc}0 \text { days } & 479 & 63.9 & 53.3 & 74.4 \\ 1 \text { or } 2 \text { days } & 94 & 12.5 & 10.7 & 14.4 \\ 3 \text { to } 5 \text { days } & 25 & 3.3 & 3.2 & 3.5 \\ 6 \text { to } 9 \text { days } & 21 & 2.8 & 3.5 & 2.1 \\ 10 \text { to } 19 \text { days } & 16 & 2.1 & 4.0 & 0.3 \\ 20 \text { to } 29 \text { days } & 20 & 2.7 & 4.5 & 0.8 \\ \text { All } 30 \text { days } & 95 & 12.7 & 20.8 & 4.5\end{array}$

Number of cigarettes smoked per day during the past 30 days

Did not smoke cigarettes during the past 30 days

Less than 1 cigarette per day

1 cigarette per day

2 to 5 cigarettes per day

6 to 10 cigarettes per day

11 to 20 cigarettes per day

More than 20 cigarettes per day

479

78

51

50

30

40

22

Had smoked cigarettes on school property during

$$
\begin{gathered}
\text { the past } \mathbf{3 0} \text { days } \\
0 \text { days } \\
1 \text { or } 2 \text { days } \\
3 \text { to } 5 \text { days } \\
6 \text { to } 9 \text { days } \\
10 \text { to } 19 \text { days } \\
20 \text { to } 29 \text { days } \\
\text { All } 30 \text { days }
\end{gathered}
$$

664

16

11

12

14

5

28

Had parents or guardians who smoked any form of tobacco

$$
\text { Neither }
$$

My father or male guardian

My mother or female guardian

$$
\text { Both }
$$

I do not know

63.9
10.4
6.8
6.7
4.0
5.3
3.0

53.3

9.6

4.8

10.9

6.4

9.6

5.3

$X^{2}=77.56$

$\mathrm{p}=0.00^{*}$

0.3

0.8

4.5

(

$\begin{array}{ccccc}323 & 43.1 & 43.7 & 42.4 & \\ 313 & 41.7 & 45.9 & 37.6 & X^{2}=15.00 \\ 18 & 2.4 & 1.3 & 3.5 & \mathrm{p}=0.00^{*} \\ 86 & 11.5 & 8.3 & 14.7 & \\ 10 & 1.3 & 0.8 & 1.9 & \\ & & & & \end{array}$

\footnotetext{
"Significant at $\mathrm{p}<0.05$; \% Percentage.
} 
(45.1\%) in Oman [18]. Thus, it is very important to assess reasons of decreased breakfast intake by students, which in this study related to not having time for breakfast that was considered as a major reason.

Furthermore, findings related to nutritional patterns were worrying. The majority of students did not meet the required amount of fruits (three servings), vegetables (four servings), milk or dairy products (five servings), as recommended by Center for Disease Control and Prevention [20]. In this study, the percentage of adolescents eating fruits four or more times daily (6.1\%) is low compared to Bahrain study (13.6\%) [19], and previous studies in Jordan (25.2\%) and (22.5\%), respectively [10] [11].

Findings of this study indicated that there is lack of consumption of milk and dairy products and critically high consumption of soft drinks. This study found that $38.9 \%$ of students had drunk soft drinks two to four times or more daily, which is consistent with Center for Disease Control and Prevention study [10], which showed that only $38.1 \%$ of the students had drunk carbonated soft drinks. On the contrary, another previous study showed that $47.3 \%$ of Jordanian students had drunk soft drinks two to four times or more daily [11]. This means that the rate of drinking soft drinks was high then going up and now is going down but still high. Previous studies showed that soft drinks consumption might be an indicator of an unhealthy, sedentary lifestyle [21] and poor diet quality [22]. Soft drinks are thought that it could displace milk in diets of children and adolescents and therefore it might affect variables of bone modeling and remodeling [23]. Some studies indicated that consumption of soft drinks might affect bone mineral density (BMD) and the risk of bone fractures in teenage girls [24]. The trend of increasing soft drinks consumption and decreasing milk consumption need concern from the health care professionals.

Furthermore, accessibility to unhealthy foods is another possible environmental determinant that can affect nutritional habits. Unhealthy foods are easily available to many adolescents. Media messages are another potentially important antecedent of adolescent nutrition. Moreover, most of television programs' commercials are advertisements for unhealthy foods and there are almost no commercials for fruits and vegetables [10].

\subsection{Physical Activity}

Regular physical activity may help improve students' academic performance, including academic achievement and grades, academic behavior, such as time on task and factors that influence academic achievement, such as concentration and attentiveness in the classroom [15]. The results of this study showed that the majority of students did not meet the required amount of physical activity as recommended by U.S. Department of Health and Human Services [25]. Almost one-fifth of students (20.1\%) had been physically active all seven days for at least 60 minutes daily. It is worthy knowing that Jordanian adolescents are more active than Omani (16.0\%) [18], Yemeni (15.2\%) [26] and Moroccan adolescent students (14.4\%) [27]. While they are low active compared to U.S. (27.1\%) [15] and Bahraini adolescents (41.7\%) [19].

The present findings further showed that only $10.4 \%$ of students had participated in muscle strengthening exercises (e.g., push-ups, sit-ups, or weight lifting) on three or more days weekly. This result is inconsistent with U.S. Center for Disease Control and Prevention study [15], which found that 51.7\% of students had participated in muscle strengthening exercises on three or more days weekly. This might be related to many cultural and environmental factors such as lack of safe youth center that meet adolescents' needs and leisure time exists that could be considered as barriers for participation in muscle strengthening exercises especially for females.

Moreover, the results of this study showed that $47.5 \%$ of students spent three or more hours daily watching T.V on an average school day. This result is inconsistent with U.S. Center for Disease Control and Prevention study [15], which showed that $32.5 \%$ of students watched television three or more hours. This could be explained by most of the Jordanian adolescents considered T.V as the best recreational facility and through it they can follow the favorite programs. The present findings further showed that $27.0 \%$ of adolescents spent three or more hours daily playing video or computer games or using a computer for something that is not schoolwork on an average school day. This result is low compared to U.S. Center for Disease Control and Prevention study [15].

This study found that $17.6 \%$ of students attended physical education (PE) classes in schools on one or more days in an average week. This result is low compared to previous studies [15] [18], which might be due to lack of time management among teachers in some schools in which they get benefit from the physical education classes to finish the required curriculum especially in the second secondary grades. Thus, data related to physical activity patterns is alarming. Therefore, serious interventions are needed to improve Jordanian adolescents' 
physical health and wellness behaviors.

\subsection{Tobacco Use}

Almost all smokers initiate cigarette smoking during adolescence, a phase that is influenced by home habits and the social and school context [28] [29]. Findings of this study showed that the majority of students (55.5\%) had tried smoking. It is worth knowing that this result is higher than previous studies conducted in Egypt (53.0\%) [30], U.S. (41.1\%) [15], Saudi Arabia (22.3\%) [31] and Tunisia (16.0\%) [32]. In addition, in this study, 44.5\% of female students had tried smoking. These findings might be due to many reasons such as feeling pleasure, curiosity, feeling more mature and independent, and reducing stress.

The study showed that $16.7 \% \%$ of students had smoked at the age of 13 or 14 years, this result is inconsistent with previous studies in U.S. (9.3\%) [15] and Tunisia (45.8\%) [32]. The present findings further showed that about one-third of students (36.1\%) had smoked cigarettes on at least one day and $15.4 \%$. of students had smoked cigarettes on 20 or more days. These findings are higher than Center for Disease Control and Prevention study [15], which reported that $15.7 \%$ of students had smoked cigarettes on at least one day and $5.6 \%$ of students had smoked cigarettes on 20 or more days. Not surprisingly, cigarette smoking was more prevalent and common among smokers, which could be explained by cigarettes being more available, easier to use and cheaper than other forms. Moreover, the result of this study is consistent with Center for Disease Control and Prevention study [15], which showed that $8.3 \%$ of students had smoked more than ten cigarettes per day on the days they smoked.

The present findings further showed that $23.2 \%$ of students had usually obtained their own cigarettes by buying. Furthermore, the prevalence of obtaining cigarettes by buying was higher among males than females. This might be related to stigma in which female smokers may be ashamed to admit that they smoke since smoking is not socially acceptable among females in Jordanian society, therefore they use other methods such as taking them from a family store or family member.

The alarming problem is smoking cigarettes on school property; this study found that $11.5 \%$ of students had smoked cigarettes on school property on at least one day. This result is high compared to a U.S. Center for Disease Control and Prevention study [15], which found that 3.8\% of students had smoked cigarettes on school property. This finding might be a proof that the schools are unfortunately a suitable environment for smoking; therefore, more restrictions are needed toward this problem.

The present findings further showed that $44.0 \%$ of students had smoked any other form of tobacco such as water pipe on at least 1 day. This result is high compared with previous studies in Tunisia [32] and U.S. [15]. Moreover, the result of this study showed that $22.5 \%$ of students had tried to quit smoking. This finding is low compared with U.S. Center for Disease Control and Prevention study [15], which found that $48.0 \%$ had tried to quit smoking. This finding might be related to many factors such as lack of awareness among students regarding the harmful effects of smoking upon their health and lack of educational programs regarding methods of quitting smoking. In addition, more than one-third of students had a parent or guardian use any form of tobacco. This may be an important reason for initiating smoking. A parent is a role model for his/her children and they imitate his/her healthy or unhealthy behaviors.

\section{Limitations}

Students participated in this study were limited to the public schools in Amman governorate and to students aged 15 to 19 years old, therefore, are not representative of all adolescents in this age group in Jordan. In addition, the extent of underreporting or over-reporting of behaviors cannot be determined; some students may not provide valid answers and may also underreport or over-report the level of health risk behaviors since the data collected are based on a self-administered questionnaire.

\section{Conclusion}

Jordanian adolescent students exhibited various patterns of health-risk behaviors and they involved in a sedentary lifestyle. The study revealed that there are problems with Jordanian adolescents relating to diet, physical activity, and tobacco use. The results indicated that there is a need for effective school health program that combines education, counseling and behavioral skill building along with environmental support to enhance students' 
efforts, intentions, and strategies to overcome these risk behaviors. Therefore, schools can help adolescents adopt and maintain healthy behaviors and implement policies and practices that effectively promote healthy choices and behaviors among students. In addition, the findings could help policy makers to strength strategies and policies to maintain healthy adolescents and schools. In order to encourage healthy schools, the Ministry of Education through education and prevention measures could implement an active school health program. The efforts should be coordinated with practically the whole of society and students to combat these behaviors through a national school health program. Having further understanding about family perspectives is also required to gain an exhaustive description about the potential family role in modifying adolescents' heath patterns. In addition, future research is strongly recommended to include wider adolescents' population in different geographical locations and wider age categories.

\section{Acknowledgements}

This research is funded by the "Deanship of Research and Graduate Studies in Zarqa University/Jordan".

\section{References}

[1] Smetana, J.G., Campione-Barr, N. and Metzger, A. (2006) Adolescent Development in Interpersonal and Societal Contexts. Annual Review of Psychology, 57, 255-284. http://dx.doi.org/10.1146/annurev.psych.57.102904.190124

[2] Mulye, T.P., Park, M.J., Nelson, C.D., Adams, S.A., Irwin, C.E. and Brindis, C.D. (2009) Trends in Adolescent and Young Adult Health in the United States. Journal of Adolescent Health, 45, 8-24.

http://download.journals.elsevierhealth.com/pdfs/journals/1054-139X/PIIS1054139X09001244.pdf http://dx.doi.org/10.1016/j.jadohealth.2009.03.013

[3] McNeely, C. and Blanchard, J. (2009) The Teen Years Explained: A Guide to Healthy Adolescent Development. Johns Hopkins Bloomberg School of Public Health, Center for Adolescent Health, Baltimore. http://www.jhsph.edu/adolescenthealth

[4] Palamara, P., Molnar, L., Eby, D., Kopinanthan, C., Langford, J., Gorman, J. and Broughton, M. (2012) Review of Young Driver Risk Taking and Its Association with Other Risk Taking Behaviors. Curtin Monash Accident Research Centre and Michigan Centre for advancing Safe Transportation through the Lifespan. http://deepblue.lib.umich.edu/bitstream/handle/2027.42/94210/102889.pdf?sequence=1

[5] Center for Disease Control and Prevention (2011) School Health Programs: Improving the Health of Our Nation's Youth. National Center for Chronic Disease Prevention and Health Promotion, Division of Adolescent and School Health, Atlanta. http://www.cdc.gov/HealthyYouth

[6] Lawrence, R.S., Gootman, J.A. and Sim, L.J., Eds., National Research Council and Institute of Medicine. Committee on Adolescent Health Care Services and Models of Care for Treatment, Prevention, and Healthy Development (2009) Adolescent Health Services: Missing Opportunities. National Academies Press, Washington. http://books.nap.edu/openbook.php?record_id=12063\&page=1

[7] World Health Organization (2014) Adolescent Health. www.who.int/adolescent_health/en/

[8] Department of Statistics (2012) Jordan Statistical Yearbook 2012. www.dos.gov.jo/dos home e/main/index.htm

[9] Center for Disease Control and Prevention (2004) Global School-Based Student Health Survey. Jordan GSHS Report, CDC and World Health Organization.

[10] Center for Disease Control and Prevention (2007) Global School-Based Student Health Survey. Jordan GSHS Report, CDC and World Health Organization.

[11] Haddad, L.G., Owies, A. and Mansour, A. (2009) Wellness Appraisal among Adolescents in Jordan: A Model from a Developing Country: A Cross-Sectional Questionnaire Survey. Health Promotion International, 24, 130-139. http://dx.doi.org/10.1093/heapro/dap013

[12] World Health Organization (2011) Young People: Risks and Solutions. www.who.int/mediacentre/factsheets/fs345/

[13] Youth Risk Behavior Surveillance-United States, 2005. http://www.cdc.gov/mmwr/PDF/SS/SS5505.pdf

[14] Cohen, J. (1992) A Power Primer. Psychological Bulletin, 112, 155-159. http://dx.doi.org/10.1037/0033-2909.112.1.155

[15] Center for Disease Control and Prevention (2013) Youth Risk Behavior Surveillance-United States, Morbidity and Mortality Weekly Report (MMWR), Vol. 63. U.S. Department of Health and Human Services and CDC. http://www.cdc.gov/mmwr

[16] Center for Disease Control and Prevention (2010) The Association between School-Based Physical Activity, Including Physical Education, and Academic Performance. U.S. Department of Health and Human Services, Atlanta. 
[17] Abu Baker, N. and Daradkeh, S. (2010) Prevalence of Overweight and Obesity among Adolescents in Irbid Governorate, Jordan. Eastern Mediterranean Health Journal, 16, 657-662.

[18] Hilmy, S.A. and Al Muzahmi, S.N. (2010) Oman Global School-Based Student Health Survey. GSHS Country Report, CDC and World Health Organization. http://www.who.int/chp/gshs/Oman_GSHS_Country_Report.pdf

[19] Serhan, N. (2010) Adolescent Health Risk Screening in Primary Care Setting. Bahrain Medical Bulletin, 32(3).

[20] Center for Disease Control and Prevention (2006) Nutrition for Everyone: Fruits and Vegetables. CDC, Georgia, Atlanta. http://www.cdc.gov/nccdphp/dnpa/nutrition/nutrition_for_everyone/fruits_vegetables/index.htm

[21] Ma, D. and Jones, G. (2004) Soft Drink and Milk Consumption, Physical Activity, Bone Mass, and Upper Limb Fractures in Children: A Population-Based Case-Control Study. Calcified Tissue International, 75, 286-291. http://dx.doi.org/10.1007/s00223-004-0274-y

[22] Libuda, L., Alexy, U., Buyken, A.E., Sichert-Hellert, W., Stehle, P. and Kersting, M. (2009) Consumption of SugarSweetened Beverages and Its Association with Nutrient Intakes and Diet Quality in German Children and Adolescents. British Journal of Nutrition, 101, 1549-1557. http://dx.doi.org/10.1017/S0007114508094671

[23] Libuda, L., Alexy, U., Remer, T., Stehle, P., Schoenau, E. and Kersting, M. (2008) Association between Long-Term Consumption of Soft Drinks and Variables of Bone Modeling and Remodeling in a Sample of Healthy German Children and Adolescents. American Journal of Clinical Nutrition, 88, 1670-1677. http://dx.doi.org/10.3945/ajcn.2008.26414

[24] McGartland, C., Robson, P.J., Murray, L., Cran, G., Savage, M.J., Watkins, D., et al. (2003) Carbonated Soft Drink Consumption and Bone Mineral Density in Adolescence: The Northern Ireland Young Hearts Project. Journal of Bone and Mineral Research, 18, 1563-1569. http://dx.doi.org/10.1359/jbmr.2003.18.9.1563

[25] U.S. Department of Health and Human Services (2008) Physical Activity Guidelines Advisory Committee Report. U.S. Department of Health and Human Services, Washington DC.

[26] Naser, N. (2008) Yemen Global School-Based Student Health Survey. GSHS Country Report, CDC and World Health Organization. http://www.cdc.gov/gshs/countries/eastmediter/yemen.htm

[27] Jabber, A. (2006) Morocco Global School-Based Student Health Survey. GSHS Country Report, CDC and World Health Organization. http://www.cdc.gov/gshs/countries/eastmediter/morocco.htm

[28] DiNapoli, P.P. (2009) Early Initiation of Tobacco Use in Adolescent Girls: Key Sociostructural Influences. Applied Nursing Research, 22, 126-132. http://dx.doi.org/10.1016/j.apnr.2007.07.001

[29] Nilsson, M., Weinehall, L., Bergström, E., Stenlund, H. and Janlert, U. (2009) Adolescent’s Perceptions and Expectations of Parental Action on Children's Smoking and Snus Use; National Cross Sectional Data from Three Decades. BMC Public Health, 9, 74. http://dx.doi.org/10.1186/1471-2458-9-74

[30] Islam, S.M. and Johnson, C.A. (2005) Influence of Known Psychosocial Smoking Risk Factors on Egyptian Adolescents' Cigarette Smoking Behavior. Health Promotion International, 20, 135-145. http://dx.doi.org/10.1093/heapro/dah604

[31] Abdalla, A.M., Al Kaaba, A.F., Saeed, A.A., Abdulrahman, B.M. and Raat, H. (2007) Gender Differences in Smoking Behavior among Adolescents in Saudi Arabia. Saudi Medical Journal, 28, 1102-1208.

[32] El Mhamdi, S., Wolfcarius-Khiari, G., Mhalla, S., Ben Salem, K. and Soltani, S.M. (2011) Prevalence and Predictors of Smoking among Adolescent Schoolchildren in Monastir, Tunisia. Eastern Mediterranean Health Journal, 17, 523528. 
Scientific Research Publishing (SCIRP) is one of the largest Open Access journal publishers. It is currently publishing more than 200 open access, online, peer-reviewed journals covering a wide range of academic disciplines. SCIRP serves the worldwide academic communities and contributes to the progress and application of science with its publication.

Other selected journals from SCIRP are listed as below. Submit your manuscript to us via either submit@scirp.org or Online Submission Portal.
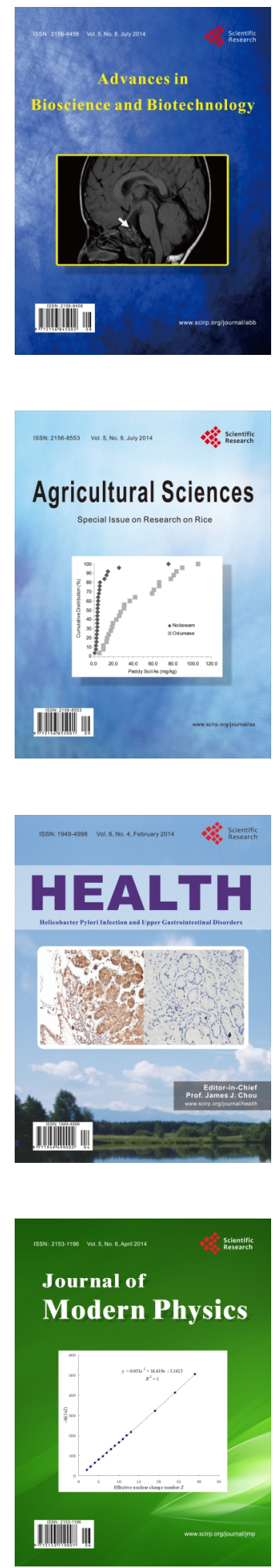
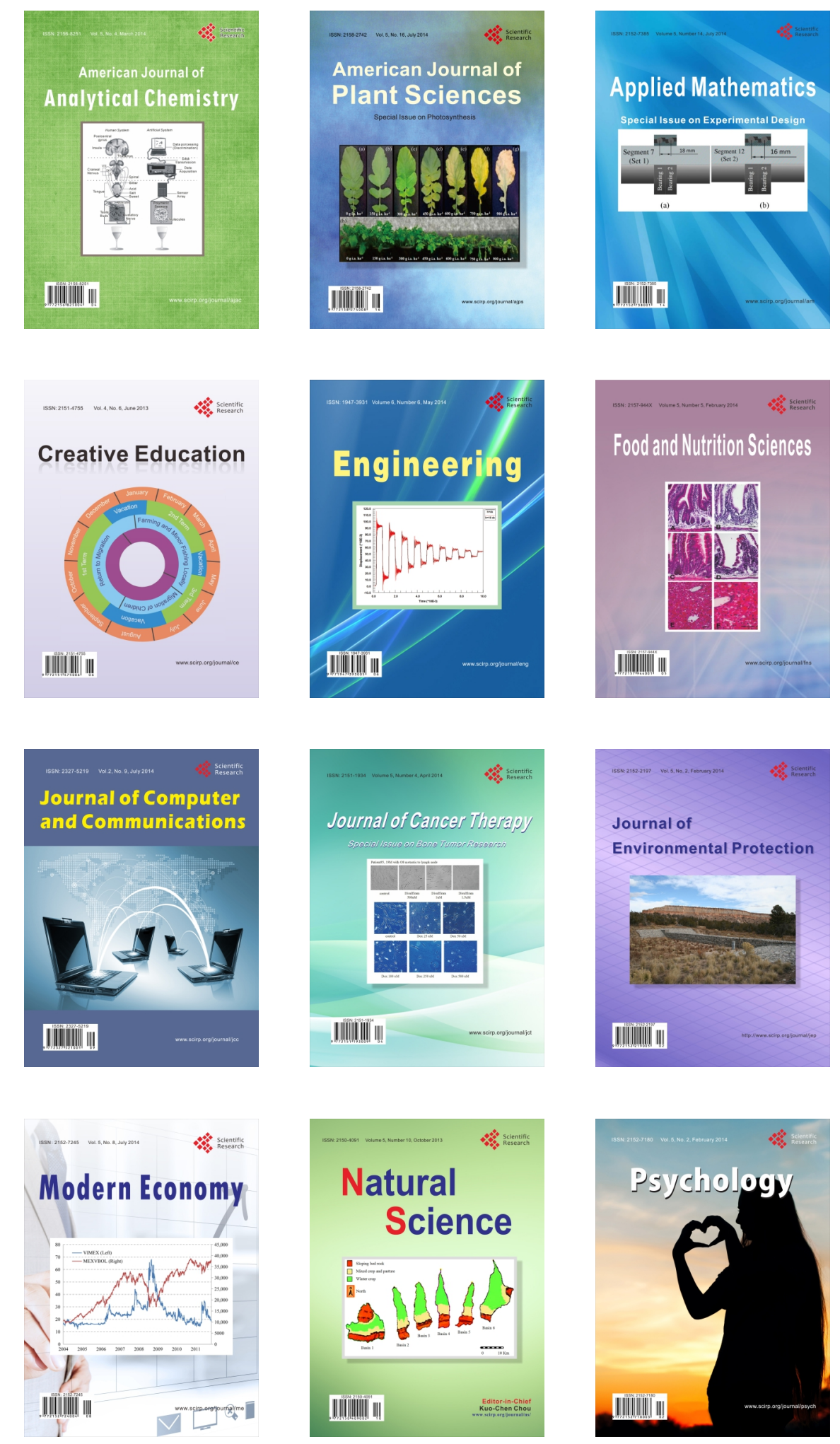